EXTENDED REPORT

\title{
Contact lenses and special back surface design after penetrating keratoplasty to improve contact lens fit and visual outcome
}

\author{
C Gruenauer-Kloevekorn, U Kloevekorn-Fischer, G I W Duncker
}

Br J Ophthalmol 2005;89:1601-1608. doi: 10.1136/bjo.2005.069500

See end of article for authors' affiliations

.....................

Correspondence to: Dr Claudia GruenauerKloevekorn, Department of Ophthalmology, MartinLuther University, ErnstGrube-Strasse 40, 06097 Halle, Germany; claudia. gruenauer-kloevekorn@ medizin.uni-halle.de

Accepted for publication 15 June 2005

\begin{abstract}
Aims: To describe the fitting of patients with high or irregular astigmatism following penetrating keratoplasty with contact lenses and to answer the question whether or not contact lenses with special back surface design can improve visual acuity in complex cases after penetrating keratoplasty.

Methods: 28 eyes were included. They were fitted with contact lenses with a special back surface that was designed for optical rehabilitation after penetrating keratoplasty. Four different types of these lenses (tricurve, keratoconus, reverse, oblong) were used selectively depending on abnormal eccentricity determined by videokeratoscope. The patients were followed up for an average period of 15.5 months. Lens tolerance and corrected visual acuity were evaluated and compared with that corrected with spectacles.

Results: The visual acuity was significantly improved in nearly all eyes with an average increase of 3.6 lines (maximal nine lines) accompanied by good contact lens tolerance and satisfactory contact lens fit. No noticeable complications were observed.

Conclusion: Contact lenses with special back surface design can improve visual results and lens tolerance, and minimise problems in contact lens fitting. This is in favour of contact lenses as an alternative to surgical procedures for correction of high or irregular astigmatism after penetrating keratoplasty. This procedure is recommended especially in cases of patients who decline further operative interventions.
\end{abstract}

$P$ ostoperative astigmatism is the main reason for unsatisfactory visual results after grafting. Various studies have shown that the number of grafts with $\leqslant 3 \mathrm{D}$ of astigmatism 2 years after transplantation ranges between $27 \%$ and $34 \%$, depending on the indication for corneal grafting. ${ }^{12}$ To achieve visual benefit and binocularity there is a strong necessity for optical or operative correction of the postoperative high astigmatism. A number of surgical and non-surgical approaches have been taken to reduce postoperative irregular astigmatism.

Surgical options for dealing with cylindrical error were already developed 40 years ago. ${ }^{34}$

Suture adjustment or selective suture removal are the first option to reduce the postoperative astigmatism..$^{5-9}$

In regular astigmatism with a well defined steep axis relaxing incisions may be beneficial. However, they are limited by the common undercorrection following a suboptimal predictability. ${ }^{10-13}$ For relaxing incisions the spherical equivalent should not exceed 1.5 dioptres. Relaxing incisions are followed by a flattening of the steep meridian and a steepening of the flat meridian (coupling effect). Thus, additional correction of the arising spherical refraction error may be necessary. ${ }^{13} 14$

There are many approaches to correct post-keratoplasty astigmatism using an excimer laser. ${ }^{15-18}$ In myopic astigmatism up to 6 dioptres a two step LASIK procedure can be performed. ${ }^{19-23}$ Although excimer laser treatment of higher degrees of astigmatism (beyond 6D) is possible, the attempted correction of higher degrees of astigmatism may expose the patient to a regression of astigmatism, poor qualitative visual outcome, and even loss of several lines of best corrected visual acuity (BCVA). ${ }^{19}$ In high astigmatism of more than 8 dioptres and in cases of cataract the implantation of a toric posterior chamber lens through a clear cornea incision at the steep axis should be preferred. ${ }^{24-26}$ In cases of irregular astigmatism, caused by an irregular transplant surface, correction by means of an excimer laser assisted by sodium hyaluronidate may be possible..$^{27}$

Complications, such as remaining astigmatism, much higher incidence of grade III to IV haze formation in the graft, and even corneal graft rejections, are mainly described after surface ablation using different excimer lasers. ${ }^{15}$ 29-31

All these surgical procedures, except for suture adjustment or selective suture removal, should be performed 3 months after removal of the keratoplasty sutures at the earliest and depend on stable conditions. ${ }^{31}$

The non-surgical approaches to the management of postkeratoplasty astigmatism include spectacles and different groups of contact lenses. Especially in those patients with high or irregular astigmatism and anisometropia sufficient visual rehabilitation can often not be achieved with spectacles. In these cases contact lens fitting is a good option.

Among the different kinds of contact lenses a rigid gas permeable lens may be the correction of choice, since this type of lens provides good visual acuity, corrects high degrees of regular and irregular astigmatism, has high oxygen permeability, and, in comparison with soft contact lenses, a lower risk for microbial keratitis (incidence 1/10 000) and for corneal neovascularisation..$^{32-34}$ Because of the special conditions after grafting, leading to changes in the corneal shape especially at the scar between graft and host cornea, in most cases only rigid gas permeable contact lenses with a special back surface design can lead to optimal fit and visual results. $^{235-37}$

The aim of this study was to determine the special corneal conditions after penetrating keratoplasty using

Abbreviations: $B C V A$, best corrected visual acuity; $\mathrm{HOA}$, higher order aberrations; RGP, rigid gas permeable; RMS, root mean square; TD, topographic disparity 
videokeratoscopic indices and to clarify which special back design may be used selectively and whether or not fitting of special back surface designed contact lenses can improve visual acuity in complex cases of high or irregular astigmatism after penetrating keratoplasty.
A
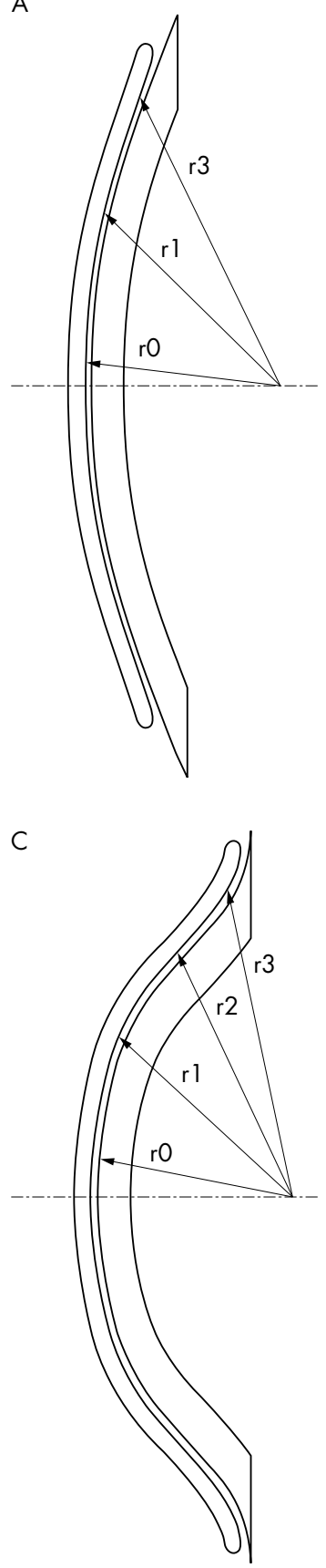

B

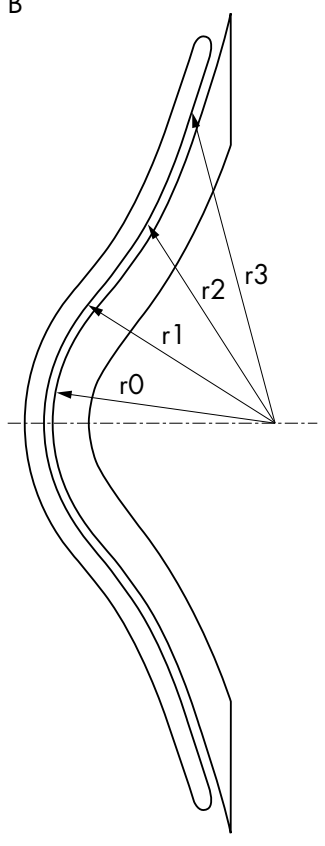

PATIENTS AND METHODS

\section{Data evaluation}

A retrospective chart review was conducted of all patients who were fitted with specially designed contact lenses following penetrating keratoplasty between January 2000 and April 2004. The data analysis of 28 eyes in 21 patients, 13 males and eight females, included age, previous ophthalmic history, corneal disorder, time from keratoplasty to contact lens fitting, preoperative visual acuity, postoperative best corrected visual acuity with spectacles, postoperative best corrected visual acuity with contact lens, contact lens back surface design, and follow up time. Corneal curvature, eccentricity $(\epsilon)$, Fourier indices, and Zernike-coefficients were performed with the Oculus computerised videokeratoscope (Oculus, Wetzlar, Germany; Software Version 1.64).

\section{Anterior surface of the cornea}

The anterior surface of the cornea has a complex shape. ${ }^{38}{ }^{39}$ To analyse this shape statistically based on its videokeratographic colour coded map, different quantitative parameters, such as Fourier series harmonic analysis, ${ }^{40}$ Zernike polynomials, ${ }^{41-45}$ or calculation of topographic disparity (TD ${ }^{46}$ by vectorial values have been developed in order to quantify the corneal irregularity. The quantification of the irregular astigmatism by calculation of topographic disparity is very useful and manageable for surgical treatment of irregular astigmatism. ${ }^{47}$ Fourier harmonic series analysis is an efficient, quantitative means of describing corneal irregular astigmatism. ${ }^{48-55}$

Fourier series harmonic analysis

Using Fourier series harmonic analysis we can decompose corneal topography data into a series of trigonomic functions

Table 1 Profile and classification of the patients and the different kinds of fitted contact lenses

\begin{tabular}{lc}
\hline Total number & 28 \\
Male & 13 \\
Female & 8 \\
Binocular & 7 \\
Age & Mean 43 years (min 20 \\
& years; max 61 years) \\
Indications for penetrating keratoplasty & \\
$\quad$ Keratoconus & 14 \\
Fuchs' dystrophy & 6 \\
$\quad$ Corneal scarring & 4 \\
Corneal ulcer & 2 \\
$\quad$ Herpes & 2 \\
Follow up time (mean) & 15.5 months (max \\
& 50 months; min 4 months) \\
Time between keratoplasty and first & 42.5 months (max \\
contact lens fitting (mean) & 336 months; min 2 months) \\
Sutures removed? & 2 \\
One & 19 \\
Both & 7 \\
No & \\
Contact lens material & 28 \\
Rigid gas permeable & 0 \\
Soft & \\
Contact lens back surface design & 10 \\
Tetracurve reverse & 11 \\
Tricurve & 5 \\
Bitoric & 3 \\
Keratoconus design & 4 \\
Oblong & \\
Contact lens front surface design & \\
Front toric & \\
\hline
\end{tabular}

Figure 1 (A) Tricurve design. $r^{0}$, central radius; $r^{1}$, connecting radius between $r^{0}$ and $r^{2} ; r^{2}$ peripheral radius. $r^{2}$ is of $0.8 \mathrm{~mm}$ smaller than $r^{0}$. (B) Keratoconus design. $r^{0}$, central radius; $r^{1} ; r^{2} ; r^{3}$ peripheral radii. The difference between $r$ and the peripheral radius $r^{2}$ is much greater than the central radius. $r^{3}$ is very flat. (C) Reverse design (tetracurve.) $r^{0}$, central radius; $r^{1} ; r^{2} ; r^{3}$ peripheral radii. $r^{2}$ is significantly steeper (reverse) than the central radius $r^{0} \cdot r^{3}$ (second reverse zone) is flatter than $r^{2}$, but steeper than $r^{0}$.
Age, follow up time, and time between keratoplasty and first contact lens fitting are giving as means.

The group of tricurve contact lenses is subdivided into one group without bitoric design (6) and one with bitoric design. The front toric design, which does not influence the back design but can improve the refraction, is part of the tricurve lenses. 
and thereby quantify each component, such as the spherical power, the regular astigmatism, asymmetry, and higher order irregular astigmatism. ${ }^{41}$

There are 21 rings for each image. Dioptric powers on a mire ring $\mathrm{i}, \mathrm{F}_{\mathrm{i}}(\sigma)$ were transformed into trigonometric components of the following form ${ }^{41}{ }^{48-51}$ :

$\mathrm{F}_{\mathrm{i}}(\sigma)=\alpha_{0}+\mathrm{c}_{1} \cos \left(\sigma-\alpha_{1}\right)+\mathrm{c}_{2} \cos 2\left(\sigma-\alpha_{2}\right)+\mathrm{c}_{3} \cos 3\left(\sigma-\alpha_{3}\right)+\ldots$

$+\mathrm{c}_{\mathrm{n}} \cos \left(\sigma-\alpha_{\mathrm{n}}\right)$

The resulting components of all rings are regrouped and displayed in separate images, where zero order $\left(a_{0}\right)$ is the spherical equivalent, first order $\left(2 \mathrm{c}_{1}\right)$ is the asymmetry component (tilt or decentration), second order $\left(2 \mathrm{c}_{2}\right)$ is the regular astigmatism component and third and higher orders $\left(c_{3} \ldots \mathrm{n}\right)$ are the higher order irregularity component. Among these, spherical equivalent power $\mathrm{a}_{0}$ and regular astigmatism $\left(2 \mathrm{c}_{2}\right)$ can be corrected by a spherocylindrical lens, while the remaining components $\left(2 \mathrm{c}_{1} ; \mathrm{c}_{3} \ldots \mathrm{n}\right)$ cannot. $2 \mathrm{c}_{1}$ and $\mathrm{c}_{3 \ldots \mathrm{n}}$ represent corneal irregular astigmatism.

The normal range of the Fourier indices are defined as the mean (2 SD) in normal eyes as described at Tanabe et al, which are 40.81-47.13D for spherical power, 0-1.04D for regular astigmatism, $0.02-0.68 \mathrm{D}$ for asymmetry, and 0.05$0.17 \mathrm{D}$ for higher order irregularity. ${ }^{50}$

\section{Zernike coefficients}

Optical aberrations of the human eye have a major role in the degrading retinal image quality..$^{4-45} 56$ They are typically described in terms of wavefront error. Wavefront error is the difference between the ideal wavefront and the actual wavefront error of the optical system. Such deviations are commonly classified by means of Zernike polynomials. ${ }^{45}$ Among this group, the Zernike coefficients from the third
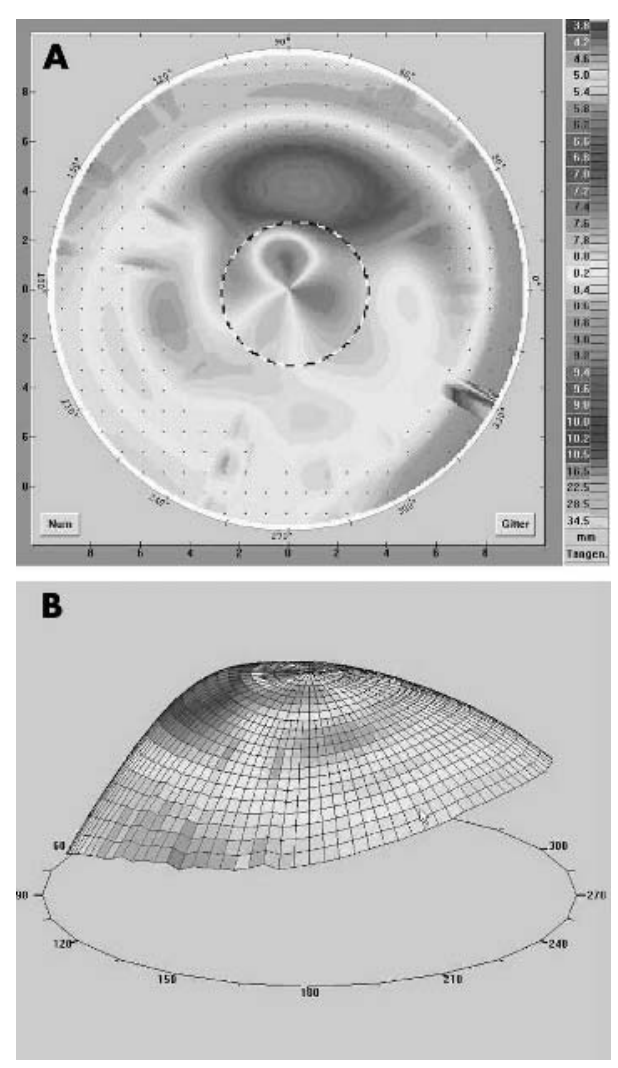

Figure 2 (A, B) Videokeratography in a case of $0 \leqslant \epsilon \leqslant 0.4$ (patient 6 in table 2). There is a steep central graft and a flatter peripheral host. With a tricurve designed lens (fig 1A) we reached an improvement of visual acuity of three lines with a good contact lens fit. Remaining astigmatism after the first fitting was corrected by an additional front toric design. to the sixth order describe the higher order aberrations (HOA), which are related to symptoms such as halo, glare, and decreased contrast sensitivity. ${ }^{56} 57$ There is a wide individual variability in anterior corneal aberrations and this is also influenced by age related changes..$^{56}$

From the Zernike coefficients, we calculated the root mean square (RMS) of higher order aberrations (HOA, square root of the sum of the squared coefficients of orders 3 up to 6). The normal range of the HOA RMS error is defined as the mean (2 SD) in normal eyes as described by Wang et al, which is $0.234-0.857 \mu \mathrm{m} .^{56}$

\section{Eccentricity}

The application of mathematical equations for an ellipse is very useful and manageable for contact lens fitting. A common approach is to use the central radius of the ellipse on the one hand and the eccentricity, $\epsilon$, the shape factor, $p$, or the asphericity, Q, on the other hand..$^{58}$ These factors describe the changing of the radius towards the periphery. The shape factor $\mathrm{p}$ and the asphericity $\mathrm{Q}$ are results of further calculations using the eccentricity $\epsilon .^{58} 59$

$\epsilon=(1 / \sin \alpha) \times \sqrt{ } 1-\left(\mathrm{r}_{0} / \mathrm{r}_{\mathrm{s}}\right)^{2}$

where $\epsilon=$ eccentricity, $\alpha=$ measurement angle, $r_{0}=$ central radius, $\mathrm{r}_{\mathrm{s}}=$ sagittal radius

$\mathrm{p}=1-\epsilon^{2}$

where $\mathrm{p}=$ shape factor

$\mathrm{Q}=-\epsilon^{2}$

where $\mathrm{Q}=$ asphericity.

In healthy corneas the eccentricity lies between 0.5 and 0.7 .5859
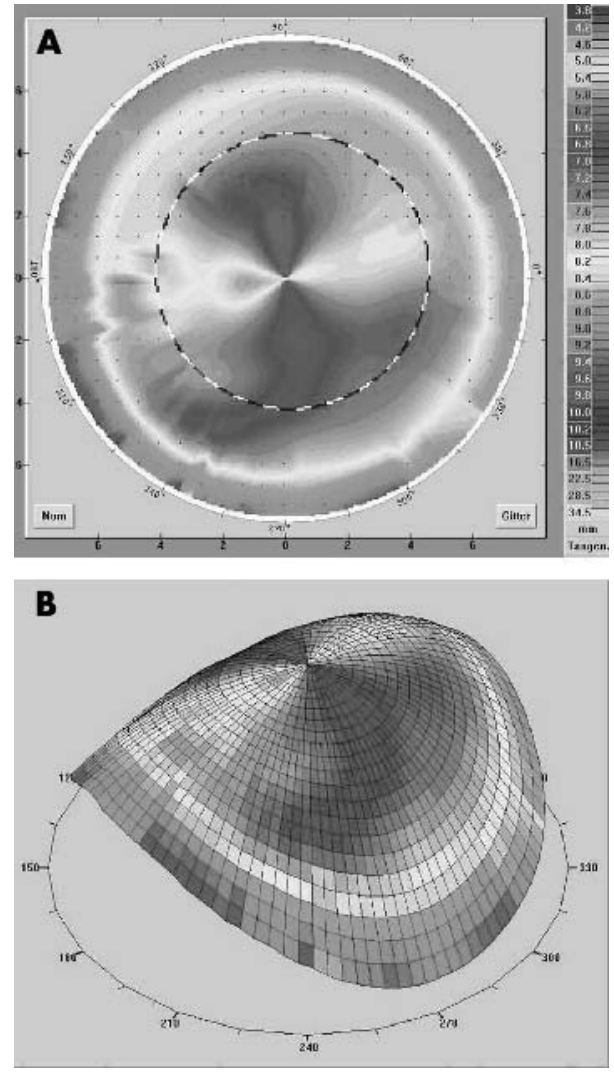

Figure 3 (A, B) Videokeratography in a case of $0 \leqslant \epsilon \leqslant 0.4$ and astigmatism within the graft as well as within the host (patient 11 in table 2). In this case for optimal contact lens fit we chose a bitoric tricurve design mostly independent of the eccentricity. We achieved an improved visual acuity of four lines with a good contact lens fit. 

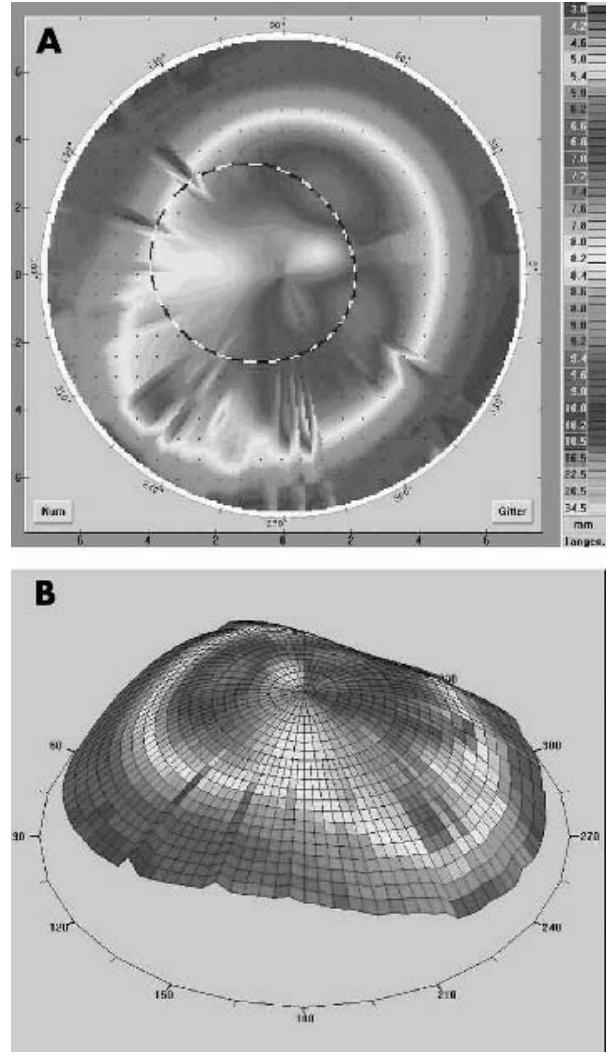

Figure 4 (A, B) Videokeratography in a case of $0.7 \leqslant \epsilon \leqslant 0.9$ (patient 14 in table 2). We fitted a keratoconus designed lens (fig 1B) and achieved an improvement of visual acuity of two lines with a good contact lens fit.
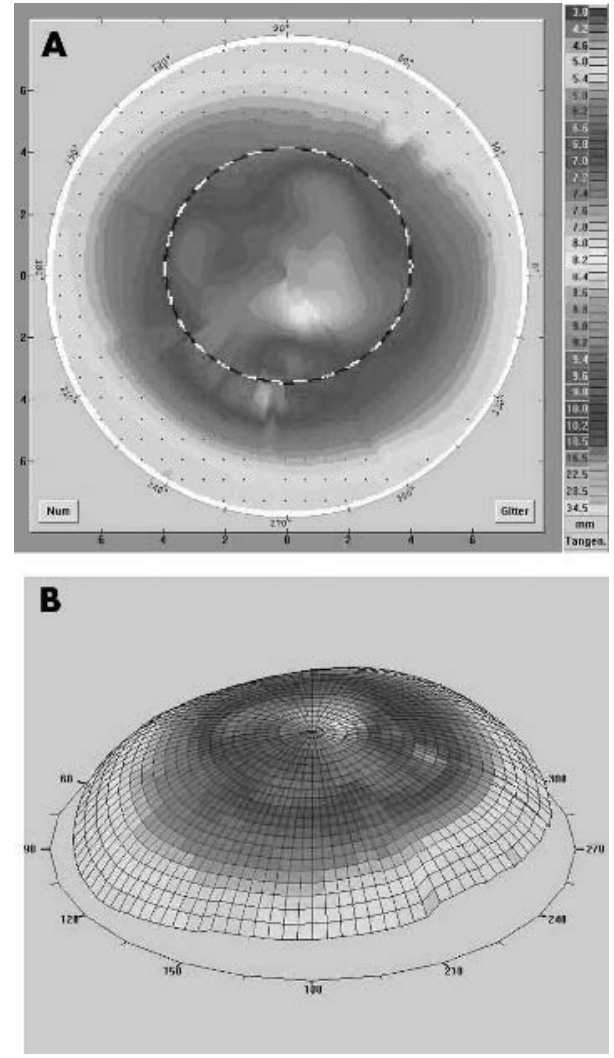

Figure $5(A, B)$ Videokeratography in a case of negative eccentricity (patient 27 in table 2). There is a flat central graft and a steep peripheral host. With a reverse designed lens (oblong; fig $1 \mathrm{C}$ ) we reached an improvement of visual acuity of seven lines with a good contact lens fit.
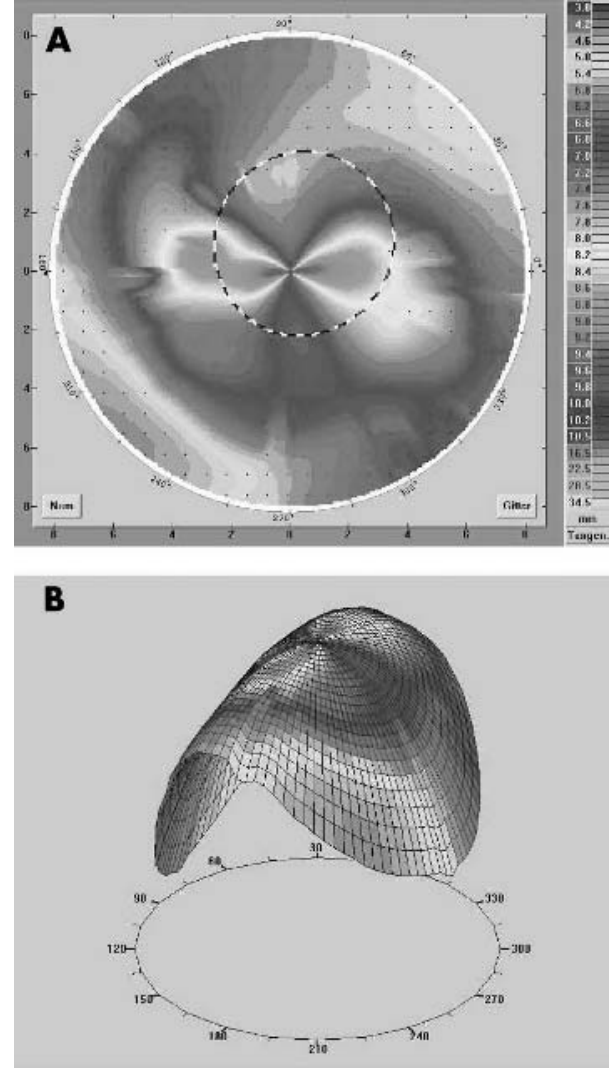

Figure 6 (A, B) Videokeratography in a case of extremely steep host and high central astigmatism (patient 26 in table 2). With a reverse designed lens (oblong; fig 1C) we reached an improvement of visual acuity of three lines limited by a cataract. The contact lens fit was tolerable.

A specific eccentricity is calculated especially in eyes after penetrating keratoplasty. ${ }^{2}$ The eccentricity increases in size in cases of a steep graft and a flat recipient's bed. In these cases we always find a positive eccentricity, in some cases greater than 1 . The eccentricity decreases in cases of a flat graft and a steep recipient's bed. In these cases the eccentricity can be lower than 0.3 up to a negative eccentricity.

Nearly all commercially available contact lenses are evaluated by eccentricity.

Contact lens fitting and anterior surface of the cornea Depending on the central curvatures and the eccentricity of the corneas we selected the back surface design of our contact lenses. Four different kinds of special back surface contact lenses were fitted. All contact lenses were made of rigid gas permeable (RGP) material.

Tricurve design (fig 1 A)

This is the contact lens that we fit if the eccentricity is between 0 and 0.4 . The back surface design of the contact lens consists of three curves. The peripheral radius $\mathrm{r}^{2}$ is $0.8 \mathrm{~mm}$ smaller than the central radius $r^{0}$; radius $r^{1}$ connects $\mathrm{r}^{0}$ and $\mathrm{r}^{2}$.

Tricurve designed lenses are the only contact lenses with special back design that can be used in affiliation with a torical back design.

\section{Keratoconus design (fig 1B)}

This kind of back surface design can be fitted if the eccentricity is greater than 0.7 . The difference between $r^{0}$ 
and the peripheral radius $r^{2}$ is bigger and the periphery $r^{3}$ is very flat.

\section{Tetracurve reverse design (fig 1C)}

The second zone $\mathrm{r}^{2}$ of this design is significantly steeper than the central radius $r^{0}$. This is the derivation of the term reverse. We have a second reverse zone $\mathrm{r}^{3}$ which is flatter than the first reverse zone $\mathrm{r}^{2}$, but steeper than or equal to the central radius $r^{0}$. We use this contact lens in case of negative eccentricity, especially if the patient has high central astigmatism.

\section{Oblong design}

This is also a reverse designed lens and is comparable to the tetracurve variation, but the periphery becomes aspheric instead of tricurve. The eccentricity of the oblong design can change from -0.4 to -0.9 .

We also fit this kind of contact lens in cases of negative eccentricity.

\section{Backtoric and bitoric design}

In cases of regular astigmatism from the central graft up to the periphery of the host the choice of backtoric or bitoric design can improve the fit of the contact lens and additionally correct remaining astigmatism. In these cases the role of eccentricity is minimised.

\section{Patients}

Table 1 shows the profile and the classification of the 28 patients and the kinds of contact lens fitted. In none of these patients could we fit a contact lens with regular back surface design because of problematical corneal conditions after penetrating keratoplasty. The mean follow up time was 15.5 months and the time between keratoplasty and the first contact lens fitting was 42.5 months. In 19 cases both sutures were removed, in two cases one suture was removed, and in seven patients the sutures were in place. In all patients the eccentricity $\epsilon$ was outside $0.5-0.7$ and in 17 cases the eccentricity was negative. Depending on this eccentricity and on individual conditions we fitted 11 tricurve contact lenses (fig 2A and B), of which five were bitoric (fig 3A and $\mathrm{B}$ ), three contact lenses with keratoconus design (fig $4 \mathrm{~A}$ and $\mathrm{B})$, and 14 reverse contact lenses, of which 10 with a tetracurve design and four an oblong design (figs 5 and $6 \mathrm{~A}$ and $\mathrm{B}$ ). In addition, a front toric design was necessary in one patient.

Table 2 Keratometric profiles of all 28 patients

\begin{tabular}{|c|c|c|c|c|c|c|c|c|c|}
\hline \multirow[b]{4}{*}{ No } & \multirow[b]{4}{*}{ simK } & \multirow[b]{4}{*}{ Axis } & \multicolumn{5}{|c|}{ Fourier series harmonic analysis } & \multirow{4}{*}{$\begin{array}{l}\begin{array}{l}\text { Zernike } \\
\text { coefficients }\end{array} \\
\text { HOA RMS error } \\
\begin{array}{l}\text { Normal range } \\
(\mu \mathrm{m})^{56}\end{array} \\
0.234-0.857\end{array}$} & \multirow{4}{*}{$\begin{array}{l}\text { Eccentricity } \\
\text { Normal range }^{5859} \\
0.5-0.7\end{array}$} \\
\hline & & & $\begin{array}{l}\text { Spherical } \\
\text { power }\end{array}$ & $\begin{array}{l}\text { Reg ast } \\
3 \mathrm{~mm}\end{array}$ & $\begin{array}{l}\text { Reg ast } \\
6 \mathrm{~mm}\end{array}$ & Asymmetry & $\begin{array}{l}\text { Higher order } \\
\text { irregularity }\end{array}$ & & \\
\hline & & & \multicolumn{5}{|c|}{ Normal range $(D)^{50}$} & & \\
\hline & & & $40.81-47.13$ & $0-1.04$ & $0-1.04$ & $0.02-0.68$ & $0.05-0.17$ & & \\
\hline \multicolumn{10}{|c|}{ Tricurve design } \\
\hline 1 & -6.8 & $43.1^{\circ}$ & 46.86 & 2.31 & 1.42 & 4.40 & 0.45 & 0.80 & 0.35 \\
\hline 2 & -4.1 & $25.9^{\circ}$ & 62.69 & 1.37 & 1.97 & 3.16 & 0.30 & 3.47 & 0.1 \\
\hline 3 & -3.8 & $143.1^{\circ}$ & 44.33 & 1.97 & 1.22 & 6.91 & 0.25 & 0.57 & 0.25 \\
\hline 4 & -7.4 & $140.9^{\circ}$ & 54.11 & 1.92 & 1.77 & 3.79 & 0.38 & 0.84 & 0.29 \\
\hline 5 & -8.7 & $11.1^{\circ}$ & 48.14 & 3.92 & 1.97 & 5.62 & 0.66 & 0.97 & 0.39 \\
\hline 6 & -1.9 & $159.5^{\circ}$ & 42.75 & 1.77 & 0.34 & 2.50 & 0.31 & 0.28 & 0.01 \\
\hline 7 & -5.5 & $9.3^{\circ}$ & 52.09 & 2.26 & 1.77 & 6.53 & 0.24 & 1.33 & -0.77 \\
\hline 8 & -5.3 & $160.3^{\circ}$ & 47.86 & 2.55 & 1.27 & 0.97 & 0.37 & 0.41 & -0.73 \\
\hline 9 & -4.8 & $158.1^{\circ}$ & 45.04 & 2.16 & 1.27 & 4.27 & 0.29 & 0.48 & 0.0 \\
\hline 10 & -3.6 & $169.3^{\circ}$ & 49.34 & 1.42 & 0.92 & 2.69 & 0.50 & 0.48 & -0.9 \\
\hline 11 & -8.8 & $11.3^{\circ}$ & 45.78 & 3.48 & 2.50 & 0.81 & 0.37 & 5.38 & 0.28 \\
\hline \multicolumn{10}{|c|}{ Keratoconus design } \\
\hline 12 & -1.8 & $141.6^{\circ}$ & 55.17 & 1.32 & 1.77 & 2.36 & 0.51 & 0.65 & 0.89 \\
\hline 13 & -7.2 & $39^{\circ}$ & 54.28 & 0.55 & 0.66 & 3.43 & 0.23 & 0.41 & 0.75 \\
\hline 14 & -2.9 & $1.7^{\circ}$ & 46.73 & 0.24 & 1.37 & 1.72 & 0.48 & 0.35 & 0.82 \\
\hline \multicolumn{10}{|c|}{ Reverse design } \\
\hline \multicolumn{10}{|c|}{ Tetracurve reverse design } \\
\hline 15 & -6.8 & $13^{\circ}$ & 52.34 & 3.43 & 1.42 & 1.87 & 0.28 & 0.62 & -0.74 \\
\hline 16 & -6.9 & $172.1^{\circ}$ & 45.28 & 2.60 & 2.07 & 2.60 & 0.29 & 0.54 & -0.32 \\
\hline 17 & -9.8 & $32.1^{\circ}$ & 47.52 & 3.57 & 2.02 & 1.97 & 0.67 & 0.70 & -0.89 \\
\hline 18 & -2.21 & $135.2^{\circ}$ & 45.28 & 5.25 & 4.53 & 3.97 & 0.19 & 1.08 & -0.35 \\
\hline 19 & -0.92 & $107.1^{\circ}$ & 49.41 & 3.97 & 3.66 & 3.79 & 0.15 & 0.96 & -0.02 \\
\hline 20 & -0.8 & $140.2^{\circ}$ & 49.34 & 0.76 & 0.34 & 1.72 & 0.21 & 0.29 & -0.22 \\
\hline 21 & -4.3 & $25.3^{\circ}$ & 43.24 & 2.02 & 2.02 & 3.92 & 0.49 & 0.50 & -0.02 \\
\hline 22 & -10.2 & $10.6^{\circ}$ & 49.93 & 3.38 & 3.43 & 4.01 & 0.23 & 1.24 & -0.12 \\
\hline 23 & -5.6 & $4.3^{\circ}$ & 46.09 & 2.12 & 1.62 & 3.34 & 0.23 & 0.60 & -0.17 \\
\hline 24 & -2.0 & $44.2^{\circ}$ & 50.76 & 1.27 & 1.02 & 3.88 & 0.29 & 0.66 & -0.07 \\
\hline \multicolumn{10}{|c|}{ Oblong reverse design } \\
\hline 25 & -9.4 & $154.1^{\circ}$ & 41.58 & 4.96 & 3.75 & 3.06 & 0.69 & 0.70 & -0.37 \\
\hline 26 & -14.8 & $0.4^{\circ}$ & 48.98 & 5.54 & 4.53 & 1.87 & 0.56 & 1.12 & -0.91 \\
\hline 27 & -1.0 & $25.9^{\circ}$ & 51.22 & 0.50 & 0.55 & 1.52 & 0.18 & 0.34 & -0.92 \\
\hline \multirow[t]{2}{*}{28} & -5.0 & $2.3^{\circ}$ & 46.47 & 2.12 & 1.37 & 2.40 & 1.03 & 0.51 & -0.38 \\
\hline & & & $\begin{array}{l}\text { Mean (SD) } \\
48.66(4.46) D\end{array}$ & $2.45(1.41) \mathrm{D}$ & $1.88(1.15)$ & $3.18(1.51) \mathrm{D}$ & 0.3910 .2010 & $0.94(1.06)$ & \\
\hline
\end{tabular}

All values out of the normal range are in italics.

All means of the Fourier series harmonic analysis and of the HOA RMS are out of the normal range.

The irregular astigmatism within the Fourier series harmonic analysis (asymmetry and higher order irregularity) is out of the normal range in all patients.

Reg ast $3 \mathrm{~mm}$, central regular astigmatism; Reg ast $6 \mathrm{~mm}$, peripher regular astigmatism.

HOA RMS error, root mean square error of the higher order aberrations (third to sixth order). 
Table 3 Profile of all 28 patients divided into the different contact lens groups

\begin{tabular}{|c|c|c|c|c|c|c|c|c|c|}
\hline No & Age/sex & $\begin{array}{l}\text { Diagnosis leading } \\
\text { to keratoplasty }\end{array}$ & $\begin{array}{l}\text { First CL } \\
\text { (months) }\end{array}$ & \multicolumn{2}{|c|}{ Central radius } & Eccentricity & Spectacle VA & CL VA & Specialties \\
\hline \multicolumn{10}{|c|}{ Tricurve design } \\
\hline 1 & $36 / M^{2}$ & Keratoconus & 17 & 7.98 & 6.88 & 0.35 & 0.5 & 0.7 & \\
\hline 2 & $65 / F$ & Fuchs' dystrophy & 6 & 6.08 & 5.66 & 0.1 & 0.02 & 0.05 & Amblyopia \\
\hline 3 & $49 / \mathrm{F}$ & Keratoconus & 336 & 8.95 & 8.12 & 0.25 & 0.2 & 0.5 & mydriasis \\
\hline 4 & $43 / M$ & Keratoconus & 48 & 7.16 & 6.18 & 0.29 & 0.2 & 0.8 & \\
\hline 5 & $37 / M$ & Herpes & 26 & 8.23 & 6.79 & 0.39 & 0.5 & 0.9 & \\
\hline 6 & $35 / M$ & Keratoconus & 12 & 8.06 & 7.72 & 0.01 & 0.3 & 0.6 & Front toric \\
\hline 7 & $49 / F$ & Fuchs' dystrophy & 60 & 7.37 & 6.58 & -0.77 & 0.6 & 0.9 & Bitoric CL \\
\hline 8 & $65 / F$ & Fuchs' dystrophy & 60 & 7.88 & 7.02 & -0.73 & 0.5 & 0.9 & Bitoric $C L$ \\
\hline 9 & $43 / M$ & Keratoconus & 12 & 8.69 & 7.81 & 0.0 & 1.0 & 1.25 & Bitoric CL \\
\hline 10 & $57 / M$ & Keratoconus & 20 & 7.92 & 7.29 & -0.9 & 0.8 & 1.0 & Bitoric CL \\
\hline 11 & $23 / M$ & Herpes & 4 & 8.27 & 6.81 & 0.28 & 0.6 & 1.0 & Bitoric CL \\
\hline \multicolumn{10}{|c|}{ Keratoconus design } \\
\hline 12 & $62 / F$ & Scarring & 17 & 6.54 & 6.32 & 0.89 & 0.2 & 0.7 & \\
\hline 13 & $61 / M$ & Fuchs' dystrophy & 60 & 7.40 & 6.78 & 0.75 & 0.05 & 0.1 & Amblyopia \\
\hline 14 & $52 / \mathrm{M}$ & Scarring & 336 & 7.49 & 7.03 & 0.82 & 0.6 & 0.8 & \\
\hline \multicolumn{10}{|c|}{ Reverse design } \\
\hline \multicolumn{10}{|c|}{ Tetracurve reverse design } \\
\hline 15 & $41 / M$ & Keratoconus & 8 & 7.74 & 6.69 & -0.74 & 0.2 & 0.6 & \\
\hline 16 & $36 / F$ & Ulcer & 17 & 8.18 & 7.00 & -0.32 & 0.7 & 0.9 & \\
\hline 17 & $57 / M$ & Keratoconus & 14 & 8.81 & 7.01 & -0.89 & 0.2 & 0.5 & \\
\hline 18 & $36 / M$ & Keratoconus & 60 & 6.97 & 6.85 & -0.35 & 0.5 & 1.0 & \\
\hline 19 & $36 / M$ & Keratoconus & 17 & 7.95 & 6.83 & -0.02 & 0.2 & 0.9 & \\
\hline 20 & $17 / F$ & Scarring & 15 & 6.95 & 6.83 & -0.22 & 0.4 & 0.7 & \\
\hline 21 & $46 / M$ & Scarring & 15 & 8.54 & 7.70 & -0.02 & 0.1 & 0.2 & \\
\hline 22 & $26 / F$ & Ulcer & 42 & 7.86 & 6.36 & -0.12 & 0.1 & 0.9 & \\
\hline 23 & $20 / \mathrm{F}$ & Keratoconus & 10 & 8.01 & 7.07 & -0.17 & 0.4 & 0.6 & \\
\hline 24 & $20 / F$ & Keratoconus & 2 & 6.77 & 6.51 & -0.07 & 0.4 & 0.8 & \\
\hline \multicolumn{10}{|c|}{ Oblong reverse design } \\
\hline 25 & $69 / F$ & Fuchs' dystrophy & 18 & 9.68 & 7.62 & -0.37 & 0.1 & 0.9 & \\
\hline 26 & $69 / \mathrm{F}$ & Fuchs' dystrophy & 3 & 8.76 & 6.33 & -0.91 & 0.1 & 0.4 & Cataract \\
\hline 27 & $34 / M$ & Keratoconus & 34 & 7.33 & 7.18 & -0.92 & 0.2 & 0.9 & \\
\hline 28 & $52 / M$ & Keratoconus & 12 & 7.72 & 7.38 & -0.38 & 0.1 & 0.3 & \\
\hline
\end{tabular}

\section{RESULTS}

Table 2 summarises the keratometric data and table 3 the data of contact lens fitting on all patients.

All patients had had an increased irregularity of the anterior cornea. Using Fourier series harmonic analysis 16 eyes $(57.2 \%)$ had spherical power out of the normal range, 27 eyes $(96.4 \%)$ had central and peripheral regular astigmatism out of the normal range and all eyes (100\%) had irregular astigmatism (asymmetry and higher order irregularity) out of the normal range. Using Zernike coefficients eight eyes $(28.8 \%)$ had HOA RMS error out of the normal range.

In all 28 cases good visual rehabilitation was achieved with an increase in visual acuity of up to nine lines and good

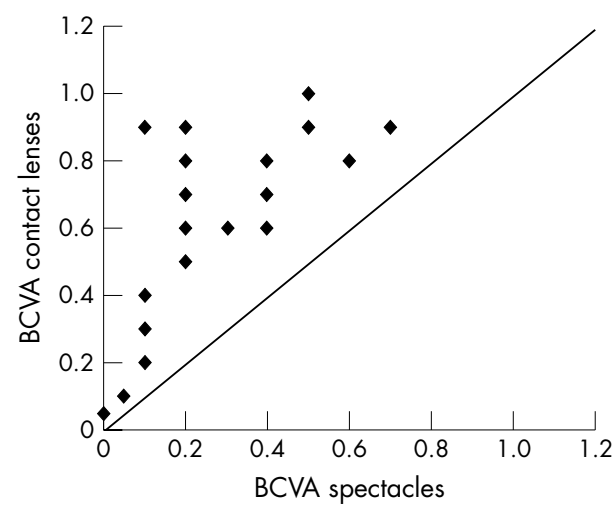

Figure 7 Scatter plot of best corrected visual acuity (BCVA) with spectacles in comparison with best corrected visual acuity with contact lens. All spots above the line indicate improvement. contact lens tolerance (CL tolerance without any disturbances for 6 hours/day).

In all patients it was possible to improve the visual acuity in comparison with best corrected visual acuity with spectacles (fig 7). The minimum improvement was one line. In two cases of monocularity in which keratoplasty on the second eye was planned the fitted contact lens led to less improvement of the visual acuity, as in one patient with high ametropia fitted with a lens to achieve binocularity. In two cases in which vision improved only minimally the reason was amblyopia, in another case a cataract and in a fourth case persisting mydriasis. We were able to achieve a satisfactory contact lens fit and we did not observe severe contact lens complications during follow up period.

\section{DISCUSSION}

Contact lens fitting has an essential role in visual rehabilitation in cases of irregularities of the corneal surface following penetrating keratoplasty and is an alternative to surgical procedures, especially in patients who decline further surgical interventions or wish transient improvement of visual acuity before further interventions are necessary.

Nevertheless, the problematic anterior corneal surface after penetrating keratoplasty can make it very difficult to achieve a sufficient correlation between anterior surface of the cornea and back surface of the contact lens and, as a result, improved visual acuity and good contact lens tolerance.

The circumstances, that in all of the examined eyes the irregular astigmatism was out the normal range and in 14 eyes $(50 \%)$ all Fourier indices were out of the normal range, demonstrate the specific corneal conditions after penetrating keratoplasty and confirm several quantitative studies on the corneal irregular astigmatism after penetrating keratoplasty. ${ }^{60} 61$ 
Additionally in eight eyes $(28.8 \%)$ we found an increased HOA RMS in comparison with nontreated eyes, which is comparable to the results of Yagci et al. ${ }^{62}$

Because of this sophisticated situation of the surfaces of graft and host, in most of the cases only rigid gas permeable contact lenses with special back design can solve all of these problems..$^{35-37}$

Publications on the fitting of contact lenses after penetrating keratoplasty are rare and often limited to fitting of only one special contact lens back surface design. Some authors describe them among a group of different corneal pathologies. Several publications are small case series or clinical opinions and none of them describe the correlation between the corneal surface and the choice of the contact lens design. ${ }^{35-37}$

To our knowledge this is the first study to demonstrate the use of rigid gas permeable contact lenses with different back designs depending on the corneal conditions (eccentricity) and to include a long term follow up of the patients of about 15 months.

We were able to fit all of our patients with contact lenses and to achieve improvement of the visual acuity and good contact lens tolerance. There were no severe complications in any of the cases.

In our opinion the most important changes in the corneal design are those towards the periphery of the cornea, which are expressed by the eccentricity. Depending on the eccentricity, contact lenses with different back surface designs can be chosen for fitting. Nevertheless individual conditions have an essential role.

Contact lenses are one alternative for correction of high or irregular astigmatism after penetrating keratoplasty that involve minor risks and bring good visual results. In our opinion, contact lenses with special back surface design can minimise problems in contact lens fitting and can improve the tolerance and the visual results. We recommend this procedure especially in cases of poor operative prognosis, for patients who decline further surgical interventions or for early postoperative correction of astigmatism.

\section{ACKNOWLEDGEMENTS}

This study was supported by the European Social Fond and the County of Sachsen-Anhalt, Germany.

\section{Authors' affiliations}

C Gruenauer-Kloevekorn, G I W Duncker, Department of Ophthalmology, Martin-Luther University, Halle, Germany U Kloevekorn-Fischer, Institute of Optometry, Trothe-Optik, Halle, Germany

\section{REFERENCES}

1 Claesson M, Armitage WJ, Fagerholm P, et al. Visual outcome in corneal grafts: a preliminary analysis of the Swedish Corneal Transplant Register. Br J Ophthalmol 2002;86:174-80.

2 Szczotka LB, Lindsay RG. Contact lens fitting following corneal graft surgery Clin Exp Optom 2003;86:244-9.

3 Krachmer JH, Fenzl RE. Surgical correction of high postkeratoplasty astigmatism. Relaxing incisions vs wedge resection. Arch Ophthalmol 1980;98:1400-2.

4 Troutman RC. Microsurgery of the anterior segment of the eye-II. St Louis: Mosby, 1977:263-286.

$5 \mathrm{McNeill} \mathrm{JI,} \mathrm{Wessels} \mathrm{IF.} \mathrm{Adjustment} \mathrm{of} \mathrm{single} \mathrm{continuous} \mathrm{suture} \mathrm{to} \mathrm{control}$ astigmatism after penetrating keratoplasty. Refract Corneal Surg 1989;5:216-23.

6 Hovding G. Suture adjustment in penetrating keratoplasty. Acta Ophthalmol 1994;72:246-52.

7 Shimazaki J, Shimmura S, Tsubota K. Intraoperative versus postoperative suture adjustment after penetrating keratoplasty. Cornea 1998;17:590-4.

8 Musch DC, Meyer RF, Sugar A. The effect of removing running sutures on astigmatism after penetrating keratoplasty. Arch Ophthalmol 1988;106:488-92.

9 Touzeau $\mathrm{O}$, Scheer S, Borderie $\mathrm{V}$, et al. Change in refraction and topography after penetrating keratoplasty suture removal. J Fr Ophtalmol 2001;24:692-703.
10 Goggin M, Alpins N, Schmid LM. Management of irregular astigmatism. Curr Opin Ophthalmol 2000;11:260-6.

11 Jain S, Azar DT, Pineda R. Management of astigmatism after corneal trauma. Int Ophthalmol Clin 2002;42:47-55.

12 Lindstrom RL. The surgical correction of astigmatism: a clinician's perspective. Refract Corneal Surg 1990;6:441-54.

13 Seiler T. Astigmatische Keratotomien. In: Refraktive Chirurgie der Hornhaut. Stuttgart New York: Georg Thieme Verlag, 2000:87-95.

14 Price F, Greene B, Marks R, et al. Astigmatism reduction clinical trial: A multicenter prospective evaluation of the predictability of arcuate keratotomy. Arch Ophthalmol 1995;113:277-82.

15 Amm M, Duncker Gl, Schroeder E. Excimer laser correction of high astigmatism after keratoplasty. J Cataract Refract Surg 1996;22:313-17.

16 Campos M, Hertzog L, Garbus J, et al. Photorefractive keratectomy for severe postkeratoplasty astigmatism. Am J Ophthalmol 1992;114:429-36.

17 McDonnell PJ, Moreira H, Garbus J, et al. Intraocular pressure changes due to vacuum fixation ring during excimer laser corneal surgery. Arch Ophthalmol 1991;109:467.

18 Spigelman AV, Albert WC, Cozean CH, et al. Treatment of myopic astigmatism with the $193 \mathrm{~nm}$ excimer laser utilizing aperture elements. $J$ Cataract Refract Surg 1994;20(Suppl):258-61.

19 Buzard K, Febbraro JL, Fundingsland BR. Laser in situ keratomileusis for the correction of residual ametropia after penetrating keratoplasty. J Cataract Refract Surg 2004;30:1006-13.

20 Malecha MA, Holland EJ. Correction of myopia and astigmatism after penetrating keratoplasty with laser in situ keratomileusis. Cornea 2002;21:564-9.

21 Hardten DR, Chittcharus A, Lindstrom RL. Long term analysis of LASIK for the correction of refractive errors after penetrating keratoplasty. Cornea 2004;23:479-89

22 Forseto AS, Francesconi CM, Nose RA, et al. Laser in situ keratomileusis to correct refractive errors after keratoplasty. J Cataract Refract Surg 1999:25:479-85.

23 Alio JL, Javaloy J, Osman AA, et al. Laser in situ keratomileusis to correct postkeratoplasty astigmatism; 1-step versus 2 -step procedure. J Cataract Refract Surg 2004;30:2303-10.

24 Gerten G, Michels A, Olmes A. Torische Intraokularlinsen. Klinische Ergebnisse und Rotationsstabilität. Ophthalmologe 2001;98:715-20.

25 Amm M, Halberstadt M. Implantation torischer Intraokularlinsen zur Korrektur des hohen Astigmatismus nach perforierender Keratoplastik. Ophthalmologe 2002;99:464-9.

26 Nuijts RM, Abhilakh Missier KA, Nabar VA, et al. Artisan toric lens implantation for correction of postkeratoplasty astigmatism. Ophthalmology 2004; 111:1086-94.

27 Alio JL, Belda Jl, Shalaby AM. Correction of irregular astigmatism with excimer laser assisted by sodium hyaluronate. Ophthalmology 2001;108:1246-60.

28 Gibralter R, Trokel SL. Correction of irregular astigmatism with the excimer laser. Ophthalmology 1994;101:1310-4.

29 Epstein RJ, Robin JB. Corneal graft rejection episode after excimer laser phototherapeutic keratectomy. Arch Ophthalmol 1994;112:157.

30 Hersh PS, Jordan AJ, Mayers M. Corneal graft rejection episode after excimer laser phototherapeutic keratectomy. Arch Ophthalmol 1993;111:735-6.

31 Lam DS, Leung AT, Wu JT, et al. How long should one wait to perform LASIK after PKP? J Cataract Refract Surg 1998;24:6-7.

32 Cheng KH, Leung SL, Hoekman HW, et al. Incidence of contact-lensassociated microbial keratitis and its related morbidity. Lancet 1999;354:181-5

33 Dart JK, Stapleton F, Minassian D. Contact lenses and other risk factors in microbial keratitis. Lancet 1991;338:650-3.

34 Chan WK, Weissman BA. Corneal pannus associated with contact lens wear. Am J Ophthalmol 1996;121:540-6.

35 Lim L, Siow KL, Sakamoto R, et al. Reverse designed contact lens wear after photorefractive keratectomy, radial keratotomy, or penetrating keratoplasty. Cornea 2000; 19:320-4.

36 Smiddy WE, Hamburg TR, Kracher GP, et al. Visual correction following penetrating keratoplasty. Ophthalmic Surg 1992;23:90-3.

37 Wietharn BE, Driebe WT Jr. Fitting contact lenses for visual rehabilitation after penetrating keratoplasty. Eye Contact Lens 2004;30:31-3.

38 Mandell RB. A guide to videokeratography. ICLC 1996;23:205-28.

39 Douthwaite WA. Contact lens optics and lens design. 2nd ed. Oxford, Boston: Butterworth-Heinemann, 1995; VIII: 334.

40 Keller P, van Saarloos P. Fourier transformation of corneal topography data. Aust N Z J Ophthalmol 1997;25(Suppl 1):S53-5.

41 Hiortdal JO, Erdmann L, Bek T. Fourier analysis of video-keratographic data. A tool for separation of spherical, regular astigmatic and irregular astigmatic corneal power components. Ophthalmic Physiol Opt 1995;15:171-85.

42 Schwiegerling J, Greivenkamp JE, Miller JM. Representation of the videokeratoscopic height data with Zernike polynomials. J Opt Soc Am A 1995; 12:2105-13.

43 Schwiegerling J, Greivenkamp JE. Using corneal height maps and polynomial decomposition to determine corneal aberrations. Optom Vis Sci 1997;74:906-16.

44 Iskander DR, Morelande MR, Collins MJ, et al. Modeling of corneal surfaces with radial polynomials. IEEE Trans Biomed Eng 2002;49:320-8.

45 Thibos LN, Applegate RA, Schwiegerling JT, et al. Standards for reporting the optical aberrations of eyes. In: Lakshminaryanan V, ed. Trends in optics and photonics. vision sciense and its applications. Vol 35. OSA Technical digest series. Washington DC: Optical Society of America, 2000:232-44.

46 Alpins NA. Treatment of irregular astigmatism. J Cataract Refract Surg 1998;24:634-46. 
47 Goggin M, Alpins N, Schmid LM. Management of irregular astigmatism. Curr Opin Ophthalmol 2000;11:260-6.

48 Oshika T, Tomidokoro A, Maruo K, et al. Quantitative evaluation of irregular astigmatism by fourier series harmonic analysis of videokeratography data. Invest Ophthalmol Vis Sci 1998;39:705-9.

49 Sciscio A, Hull CC, Stephenson CG, et al. Fourier analysis of induced irregular astigmatism. Photorefractive keratectomy versus laser in situ keratomileusis in a bilateral cohort of hyperopic patients. J Cataract Refract Surg 2003:29:1709-17.

50 Tanabe T, Tomidokoro A, Sameiima T, et al. Corneal regular and irregular astigmatism assessed by Fourier analysis of videokeratography data in normal and pathologic eyes. Ophthalmology 2004;111:752-7.

51 Baek TM, Lee KH, Tomidokoro A, et al. Corneal irregular astigmatism after laser in situ keratomileusis for myopia. Br J Ophthalmol 2001;85:534-6.

52 Schwiegerling J, Greivenkamp JE. Using corneal height maps and polynomial decomposition to determine corneal aberrations. Optom Vis $\mathrm{Sci}$ 1997;74:906-16.

53 Guirao A, Artal P. Corneal wave aberration from videokeratography: accuracy and limitations of the procedure. J Opt Soc Am A Opt Image Sci Vis 2000;17:955-65.
54 Barbero S, Marcos S, Merayo-Lloves J, et al. Validation of the estimation of corneal aberrations from videokeratography in keratoconus. J Refract Surg 2002; 18:263-70

55 Gobbe M, Guillon M, Maissa C. Measurement repeatability of corneal aberrations. J Refract Surg 2002;18:S567-71.

56 Wang L, Dai E, Koch DD, et al. Optical aberrations of the human anterior cornea. J Cataract Refract Surg 2003;29:1514-21.

57 Amano S, Amano Y, Yamagami S, et al. Age-related changes in corneal and ocular higher-order wavefront aberrations. Am J Ophthalmol 2004; 137:988-92.

58 Baron H. Kontaklinsen. Lehrbuch und Leiffaden. Heidelberg: Verlag Optische Fachveröffentlichungen, 1991:21-22, 421-4.

59 Ehrich W, Epstein D. Color atlas of contact lenses. New York: Thieme Medical Publishers, 1988:54-102, 130-9.

60 Genvert GI, Cohen EJ, Arentsen JJ, et al. Fitting gas-permeable contact lenses after penetrating keratoplasty. Am J Ophthalmol, 1985 15, 99:51 1-14.

61 Kagaya F, Tomidokoro A, Tanaka S, et al. Fourier series harmonic analysis of corneal topography following suture removal after penetrating keratoplasty. Cornea 2002;21:256-9.

62 Yagci A, Egrilmez S, Kaskaloglu M, et al. Quality of vision following clinically successful penetrating keratoplasty. I Cataract Refract Surg 2004;30:1287-94. 